\title{
Methods of Multi-objective Optimisation Design of Thin-walled Structures
}

\author{
Xiaoyang $\mathrm{Liu}^{1, \mathrm{a}}$ and Shuang $\mathrm{Qu}^{2, \mathrm{~b}}$ * \\ ${ }^{1}$ Shandong Jianzhu University, Fengming Road, Jinan, Shandong, China \\ ${ }^{2}$ Shandong Jianzhu University, Fengming Road, Jinan, Shandong, China \\ a156201223@qq.com, bqushuang@sdjzu.edu.cn
}

Keywords: Multi-objective optimisation; thin-walled structures; finite element analysis.

Abstract: In this paper, there are two objectives in the optimisation of thin-walled structure, one of these is to reduce the total mass of the structure, and the other is to ensure the carrying capacity of the structure. The secondary objective, i.e. carrying capacity, is transformed into the optimisation constraints by Constraining Method. The structure is optimized by modifying the thickness of the plate. The finite model is created using ABAQUS/CAE in the visual environment. Then the maximum carrying capacity is calculated by buckling analysis, and used as the applied load in the static analysis. The optimisation software is written by $\mathrm{VC}++$, which can automatic read the output of ABAQUS data file and use the maximum stress in each plate as a critical stress to calculate the corresponding thickness. Then a new ABAQUS input file with the new plate thicknesses is created by the software. The structure described in the example of this paper finally obtained a minimum mass with great carrying capacity, after six times of optimisation

\section{Introduction}

Structure optimisation is to find the optimal solution to meet the specified target under the given constraints [1]. Chames proposed a multi-objective programming approach to solve multi-objective optimisation problems [2].In 1968 Geoffion gave different weights to different objectives by weighted method to achieve optimisation goal, this is a huge step forward in optimisation [3]. Then A.Palazoglu optimized structure by constraining method which achieved a good result [4]. Thin-walled structures are very significant in engineering which widely used in civil engineering, aerospace engineering and mechanical engineering. S.Qu optimized an aircraft wing incorporating post-buckling effects and the study show substantial mass saving [5]. Multi-objective optimisation is more and more popular in the domain of engineering, researchers can find the optimal structure to improve performance and save material.

\section{Optimisation approach}

In multi-objective optimisation, there is no optimal solution but only the most satisfactory solution which called Pareto solution. The most effective and simple method to solve this problem is to convert the multi-objective problem into a single objective optimisation problem, then the problem can be solved by method that used to solve single optimisation problem[6]. In this paper, constraining method is used to solve this double objective optimisation, mathematical model:

$$
\left\{\begin{array}{l}
\min f(x)=f_{1}(x) \\
\text { s.t. } \quad g(x)=f_{2}(x) \\
x \in X
\end{array}\right.
$$

where, $\mathrm{f}(\mathrm{x})$ is the objective function, $\mathrm{g}(\mathrm{x})$ is the constraint, $\mathrm{x}$ is the design variables and $\mathrm{X}$ is the feasible region for the design variables. 


\section{Finite Element Analysis}

A box which only consist of 4 plates ( 2 meters in hight, 1 meters in width, 0.02 meter in thickness) is created by using finite element analysis software ABAQUS. The material is high strength graphite/epoxy $(\mathrm{E} 1=142 \mathrm{Gpa}$; $2=10 \mathrm{Gpa} ; \mathrm{G} 12=6 \mathrm{Gpa} ; \mathrm{G} 13=3.6 \mathrm{Gpa} ; \mathrm{G} 23=3.6 \mathrm{Gpa} ; \mu=0.3$ the density of graphite is $2250 \mathrm{~kg} / \mathrm{m}^{3}$ ). the connection of these 4 plates and boundary condition is simply-supported, and each plate is defined as a part. Each part are segmented into 160 elements, to guarantee the carrying capability. Firstly, the model is loaded by an uniform load of $1000 \mathrm{~N}$. Then, the critical load that the structure can carry could be obtained by the buckling analysis. Then, the static analysis is carried out with this uniform surface load is applied in the short side of each plate, i.e. longitudinal direction along the plate.

\section{Multi-objective Optimisation}

During optimisation process, in the static analysis, the critical load is applied to the structure as a constraint to achieve the double-objective optimisation.

The flow chart of the optimisation is shown in Fig. 1.

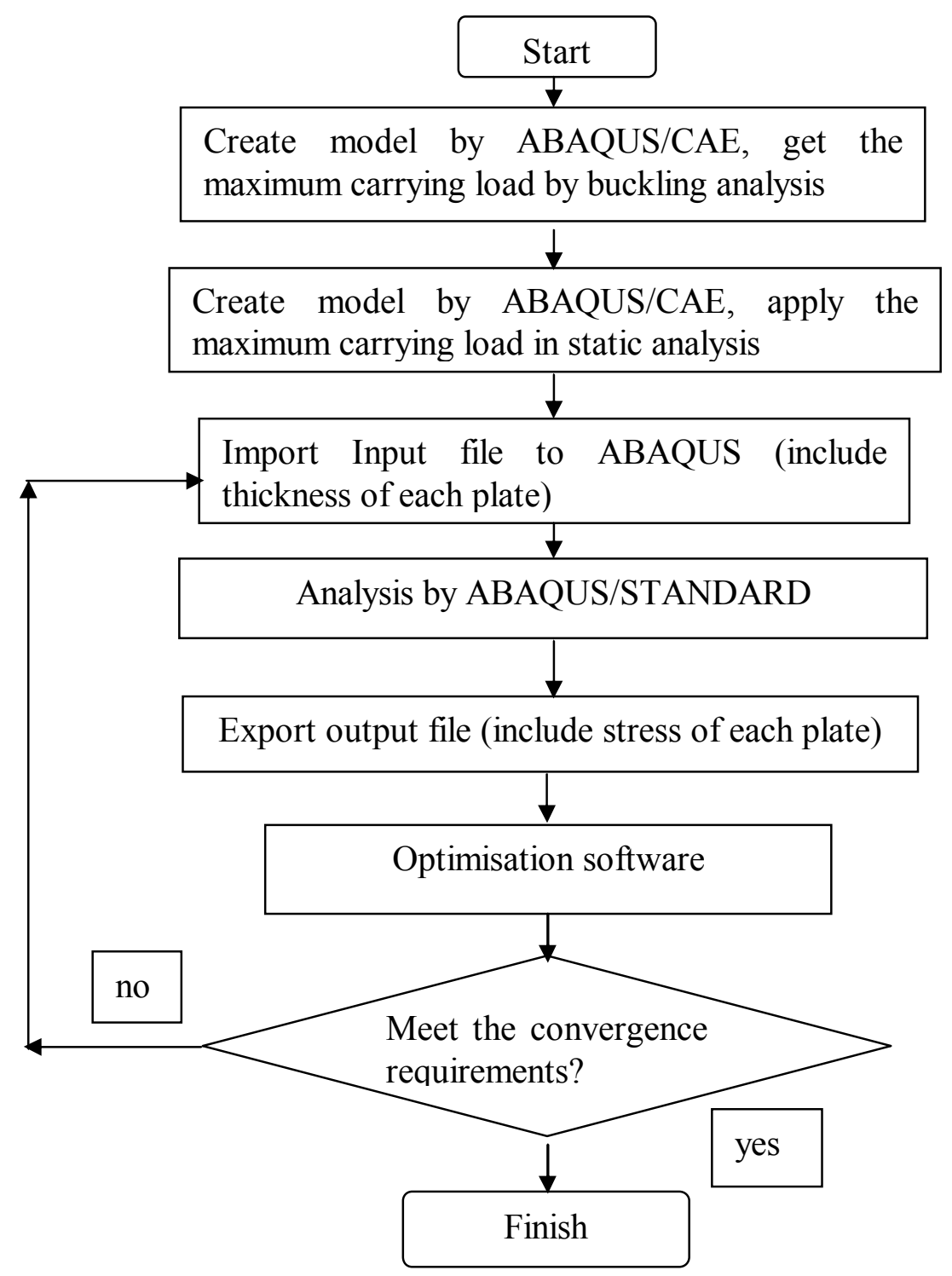

Fig. 1 The flow chart of the optimisation 
Each static analysis is processed in the background of ABAQUS by ABAQUS / COMMAND. The optimisation software is written by $\mathrm{VC}++$, which can automatic read the output of ABAQUS data file and use the maximum stress in each plate as a critical stress to calculate the corresponding thickness. The equation of thickness of the plate is

$$
t=\sqrt{\frac{12\left(1-\mu^{2}\right) \cdot \sigma_{x c r} \cdot b^{2}}{K \cdot \Pi^{2} \cdot E_{1}}}
$$

where, $\mathrm{t}$ is the thickness of plate, $\sigma_{\text {xcr }}$ is the critical load in the direction of $\mathrm{X}$ axis, $E_{1}$ is Elastic Modulus in the direction of $\mathrm{X}$ axis, $\mathrm{b}$ is the width of the plate, $\mathrm{K}$ is the buckling coefficient. $\mu$ is the poisson ratio.

Substituted $\mu=0.3, a=0.2 m, b=1 m, \beta=\frac{a}{b}=2, m=2$ and $K=4$, into the equation to get,

$$
t=0.529 \sqrt{\frac{\sigma_{x c r}}{E_{1}}}
$$

With these new plate thicknesses, a new ABAQUS input file will be created by the software. The software also calculates the total mass of the new structure and carries out the convergence check. If the structure fails to reach convergence requires, then a new ABAQUS analyses will be carried out with the new input file. Thereafter, the new maximum stress of each plate will be calculated. The optimisation cycle will be continuous until the mass of structure meets the convergence requirements, i.e. 0.01 .

The equation of mass convergence is

$$
c v[n]=\frac{M_{n}-M_{n-1}}{M_{0}}
$$

where, $\mathrm{t}$ is the thickness of plate, $\sigma_{\mathrm{xcr}}$ is the Critical load in the direction of $\mathrm{X}$ axis, $E_{1}$ is Elastic Modulus in the direction of $\mathrm{X}$ axis, $c v_{n}$ is the convergence of the $\mathrm{n}^{\text {th }}$ optimisation cycle, $M_{\mathrm{n}}$ and $M_{\mathrm{n}-1}$ are the mass of the whole structure of the $\mathrm{n}^{\text {th }}$ and the $(\mathrm{n}-1)^{\text {th }}$ optimisation cycle respectively, $M_{0}$ is the initial total mass.

\section{Results and discussion}

After six cycles of optimisation program, the mass of the structure meet the convergence requirement. The total mass is reduced from $360 \mathrm{~kg}$ to $295.04 \mathrm{~kg}$, i.e. reduced by $18 \%$. The final convergence result is 0.00754902 , which achieved the optimisation objective. The stress distribution of the structure before the optimisation is shown in Fig. 2. The stress distribution of the structure after the optimazation is shown in Fig. 3. 


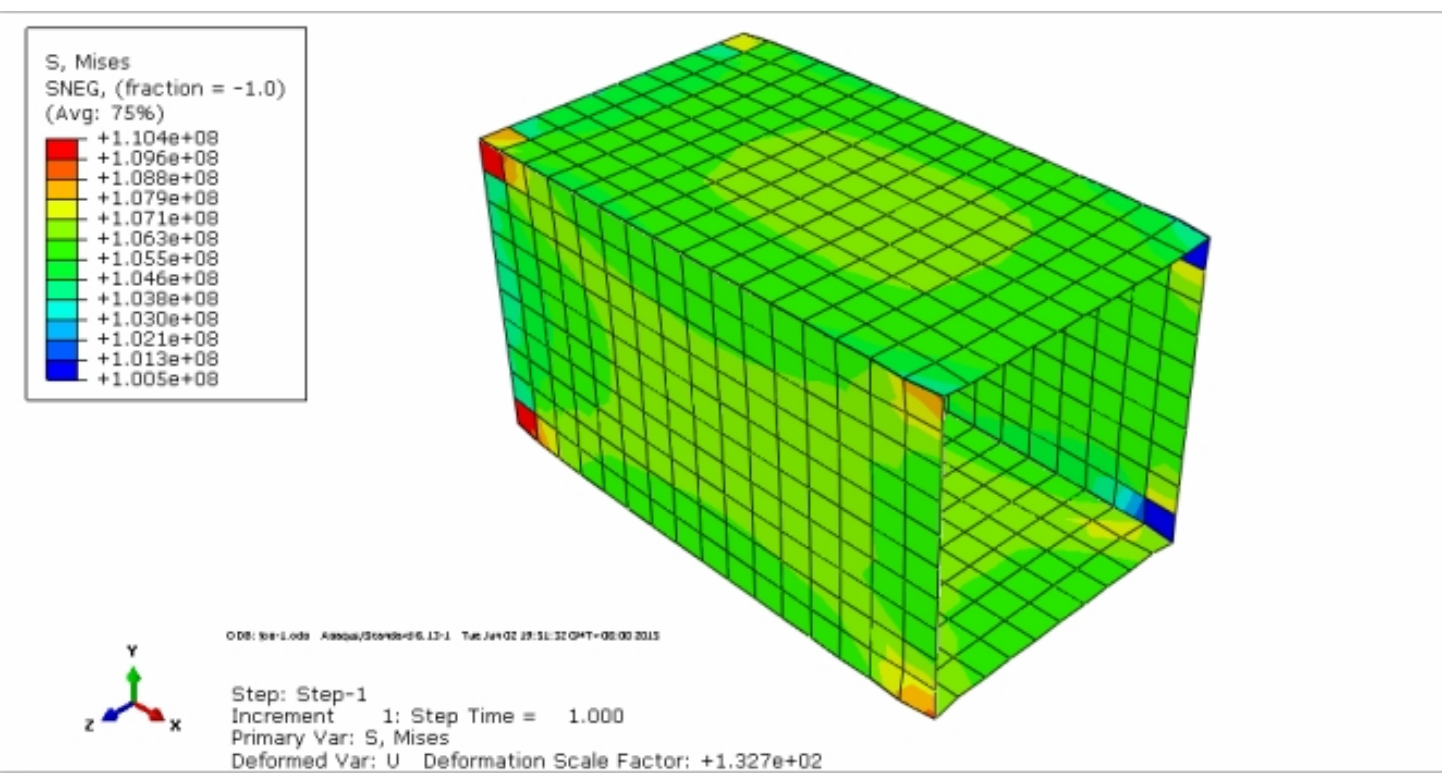

Fig. 2 Stress contours for the initial designs

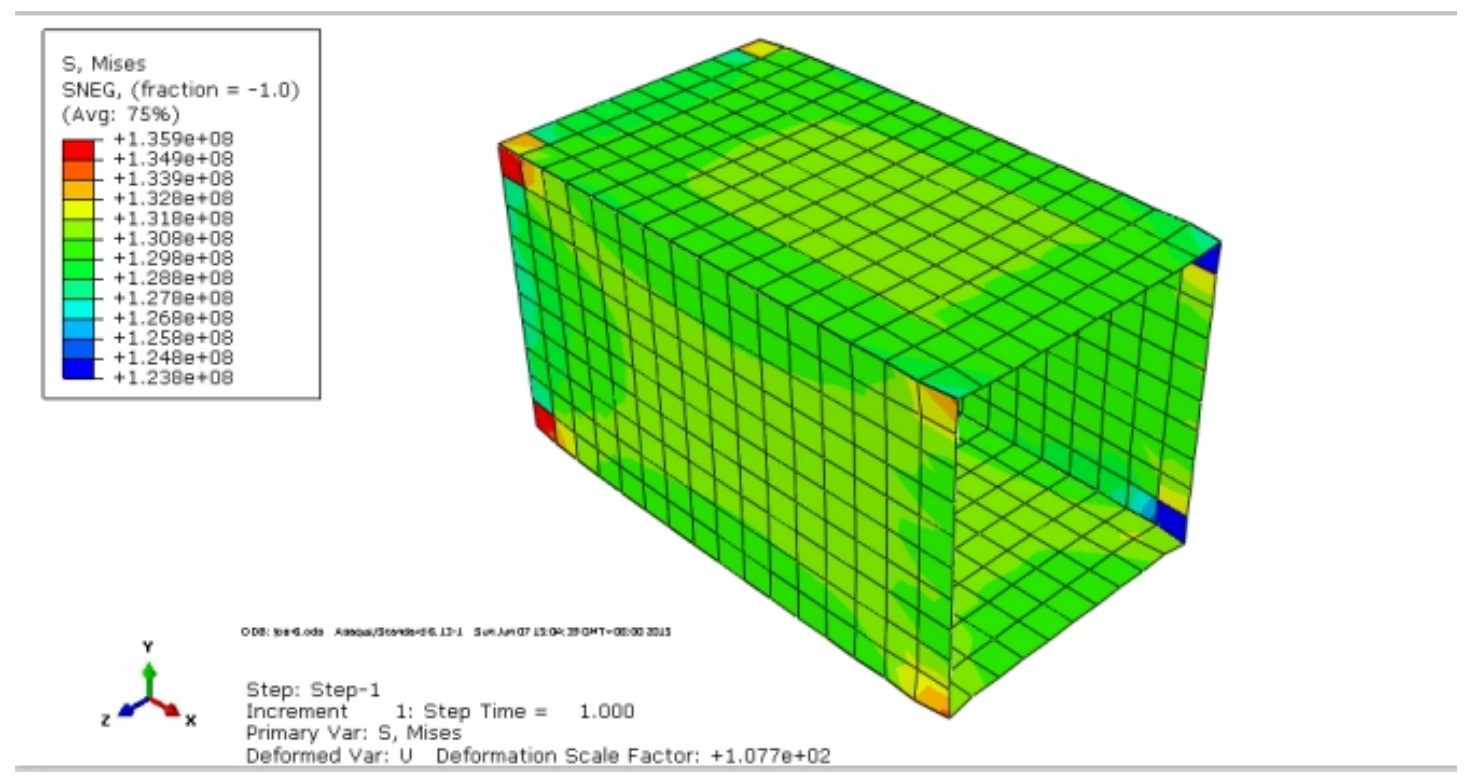

Fig. 3 Stress contours for the final designs

The maximum stress of the two parallel plates is approximate the same, due to the uniform setting of the boundary conditions, constraints, thickness and the load conditions of these two plates.

The maximum stress changes in the optimisation are given in Table 1. The stress of plates increased significantly at first, and then fluctuated and slowed down to achieve balance.

Table 2 is showing the changes of the thicknesses during the optimisation. It demonstrates that the thicknesses of plates reduced significantly at first, and then fluctuated and slowed down to achieve balance. 


\begin{tabular}{|l|c|c|c|c|}
\hline \multicolumn{5}{|c|}{ The Maximum Stresses (Pa) } \\
\hline $\begin{array}{l}\text { Design } \\
\text { Cycles }\end{array}$ & Plate 1 & Plate 2 & Plate 3 & Plate 4 \\
\hline 1 & $1.10770 \mathrm{E}+08$ & $1.10830 \mathrm{E}+08$ & $1.10770 \mathrm{E}+08$ & $1.10830 \mathrm{E}+08$ \\
\hline 2 & $1.49740 \mathrm{E}+08$ & $1.49810 \mathrm{E}+08$ & $1.49740 \mathrm{E}+08$ & $1.49810 \mathrm{E}+08$ \\
\hline 3 & $1.28880 \mathrm{E}+08$ & $1.28940 \mathrm{E}+08$ & $1.28880 \mathrm{E}+08$ & $1.28940 \mathrm{E}+08$ \\
\hline 4 & $1.38870 \mathrm{E}+08$ & $1.38940 \mathrm{E}+08$ & $1.38870 \mathrm{E}+08$ & $1.38940 \mathrm{E}+08$ \\
\hline 5 & $1.33800 \mathrm{E}+08$ & $1.33870 \mathrm{E}+08$ & $1.33800 \mathrm{E}+08$ & $1.33870 \mathrm{E}+08$ \\
\hline 6 & $1.36300 \mathrm{E}+08$ & $1.36370 \mathrm{E}+08$ & $1.36300 \mathrm{E}+08$ & $1.36370 \mathrm{E}+08$ \\
\hline
\end{tabular}

Table 1 Redistribution of maximum stresses

\begin{tabular}{|l|c|c|c|c|}
\hline \multicolumn{5}{|c|}{ The Thicknesses of The Plates (m) } \\
\hline $\begin{array}{l}\text { Design } \\
\text { Cycles }\end{array}$ & Plate 1 & Plate 2 & Plate 3 & Plate 4 \\
\hline 0 & $2.00000 \mathrm{E}-02$ & $2.00000 \mathrm{E}-02$ & $2.00000 \mathrm{E}-02$ & $2.00000 \mathrm{E}-02$ \\
\hline 1 & $1.47748 \mathrm{E}-02$ & $1.47788 \mathrm{E}-02$ & $1.47748 \mathrm{E}-02$ & $1.47788 \mathrm{E}-02$ \\
\hline 2 & $1.71783 \mathrm{E}-02$ & $1.71823 \mathrm{E}-02$ & $1.71783 \mathrm{E}-02$ & $1.71823 \mathrm{E}-02$ \\
\hline 3 & $1.59369 \mathrm{E}-02$ & $1.59406 \mathrm{E}-02$ & $1.59369 \mathrm{E}-02$ & $1.59406 \mathrm{E}-02$ \\
\hline 4 & $1.65431 \mathrm{E}-02$ & $1.65472 \mathrm{E}-02$ & $1.65431 \mathrm{E}-02$ & $1.65472 \mathrm{E}-02$ \\
\hline 5 & $1.62383 \mathrm{E}-02$ & $1.62425 \mathrm{E}-02$ & $1.62383 \mathrm{E}-02$ & $1.62425 \mathrm{E}-02$ \\
\hline 6 & $1.63893 \mathrm{E}-02$ & $1.63700 \mathrm{E}-02$ & $1.63893 \mathrm{E}-02$ & $1.63935 \mathrm{E}-02$ \\
\hline
\end{tabular}

Table 2 Changes of thicknesses

The changes of the total mass during the optimisation are shown in Fig. 4. The original mass of structure is $180 \mathrm{~kg}$. After the first cycle of the optimisation it reduced to $132.9 \mathrm{~kg}$, and then increased to $154.623 \mathrm{~kg}$. Finally, it settled at $147.522 \mathrm{~kg}$. The total reduction of the total mass is $32.478 \mathrm{~kg}$.

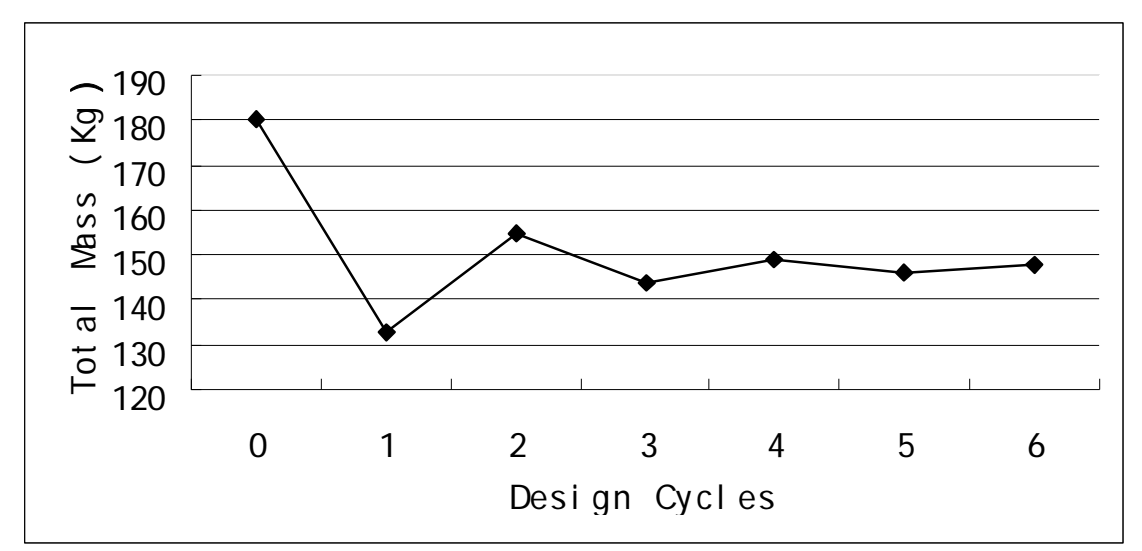

Fig. 4 Total mass changes during the optimisation

Fig. 5 shows the total mass convergence criterion varied through out the optimisation. The convergence percentage continuously reduced from 0.261158 to 0.00754902 . The convergence criterion is reached at the sixth cycle. 


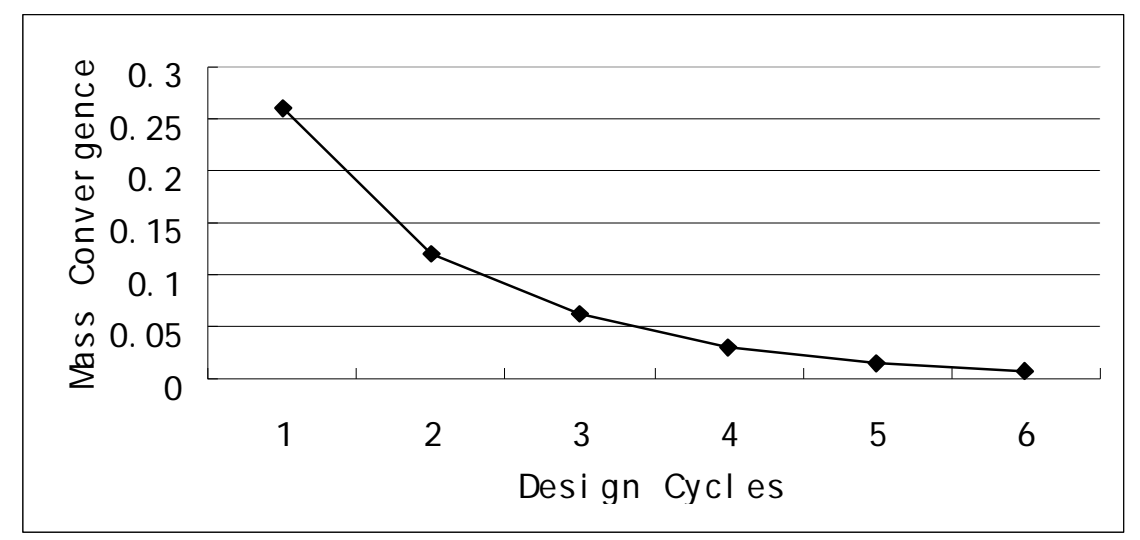

Fig. 5 The total mass convergence through out the optimisation

\section{Conclusion}

The methods of multi-objective optimisation design of thin-walled structure, which described in this paper, achieved a great goal. Constraining method was used to transform the secondary objective into a constraint. The main objective is to reduce the total mass of the structure by modifying the thickness of each plate. ABAQUS is used to create finite element mode, and calculate the maximum carrying capacity and the stress of the plates. The optimisation software is written by $\mathrm{VC}++$, which can read ABAQUS output file, write input file and check the convergence requirement. So that it can control the cycle of the optimisation.

\section{Acknowledgements}

This project sponsored by Shandong Provincial Natural Science Foundation, China (2014ZRB019XI), and SRF for ROCS, SEM.

\section{References}

[1] Altair Engineering. Engineering design optimisation course lecture notes, 2000 (Altair Engineering Ltd,Alderton, Northamptonshire, UK.

[2] A. Charnes, et al. Management science, 1995, 1 (2) 138-151.

[3] A.M. Geoffrion, Journal of Mathematical Analysis and Applications, 1968, 22(3) 618-630.

[4] A. Palazoglu and Y. Arkun, Chem. Eng. 1986, 10(6) 567-575.

[5] S. Qu, D. Kennedy, C.A. Featherston, Proceedings of the Institution of Mechanical Engineers, Part G: Journal of Aerospace Engineering, 226 (7) (2012) 830-845.

[6] L.X. Qian, Optimization design of structure, Beijing, Science Press, (2011). in Chinese. 